\title{
Theoretical calculation of self-propagating high-temperature synthesis (SHS) preparation of $\mathrm{AlB}_{12}$
}

\author{
Chao Wang $^{1 *}$, Xiaoming $\mathrm{Cao}^{2}$, Mengge Dong ${ }^{3}$, Lu Zhang ${ }^{4}$, Jianxing $\mathrm{Liu}^{3}$, Xiaozhou Cao ${ }^{3}$, and Xiangxin Xue ${ }^{3 *}$ \\ 1Department of Mechanical Engineering, the University of Texas at Dallas, Richardson, TX, 75080, USA \\ 2Institute of Metal Research, Chinese Academy of Science, Shenyang, Liaoning, 110016, China \\ ${ }^{3}$ School of Metallurgy, Northeastern University, Shenyang, Liaoning, 110819, China \\ ${ }^{4}$ School of Energy and Environment, Anhui University of Technology, Ma'anshan, 243002, China
}

Chao Wang, Xiaoming Cao, and Mengge Dong made an equal contribution.

*Corresponding author. E-mail: wang.chao@utdallas.edu, xuexx@mail.neu.edu.cn

\begin{abstract}
Although experimental results of preparing $\mathrm{AlB}_{12}$ by self-propagating high-temperature synthesis using $\mathrm{Mg}-\mathrm{B}_{2} \mathrm{O}_{3}-\mathrm{Al}_{2} \mathrm{O}_{3}$ as raw material has been studied, the theoretical calculations for the preparation of $\mathrm{AlB}_{12}$ have not been examined as thoroughly. In this article, for the first time, we report on the study of theoretical calculation and the adiabatic temperature, calculated, and compared with the actual reaction temperature. The Gibbs free energy for each level of reaction is also calculated. The calculation results show that the adiabatic temperature is $2789.5 \mathrm{~K}$, the standard Gibbs free energy of each reaction is less than 0 , and the reaction can proceed spontaneously, which is consistent with the results of the experiment.
\end{abstract}

Keywords: AlB 12 , SHS, Theoretical calculations, Adiabatic temperature, Standard Gibbs free energy

\section{Introduction}

In the process of SHS synthesis reaction research, the reaction system must meet certain thermodynamic conditions so that the reaction can self-sustain the combustion reaction process (1-3). Among them, the most basic thermodynamic parameter is the Adiabatic Temperature of the reaction (4-7). Self-propagating high-temperature synthesis (or SHS) is a chemical reaction under special conditions (8-11). Thermodynamic analysis mainly discusses the feasibility of the reaction, such as how to judge whether a chemical reaction can proceed under given conditions, to what extent, and what effect the reaction will have after changing the conditions (12-14).

Thermodynamic analysis of the combustion system is the basis for studying the SHS process (15-17). The main task of thermodynamic analysis is to calculate the combustion temperature and product balance under adiabatic conditions, that is, when all the heat released by the reaction is used to heat the product synthesized during the reaction $(18,19)$. The calculation is based on the minimum principles of conservation of mass and energy and chemical potential (Gibbs free energy) (20, 21). Thermodynamic calculation is a very effective method for studying the SHS process, as it helps to control the temperature and composition of the process products (22-25).

Previous studies have shown that $\mathrm{AlB}_{12}$ can be prepared by the self-propagating method (26-28), and the reaction temperature is higher than $2300^{\circ} \mathrm{C}$. However, the self-propagating reaction has not been calculated theoretically. In this article, the basic principle of self-propagating reaction is explained, the theoretical calculation of self-propagating preparation of $\mathrm{AlB}_{12}$ is studied, and the calculated results are compared with the actual test results. 


\section{Principle of self-propagating reaction}

Adiabatic temperature is an important thermodynamic parameter describing the characteristics of combustion synthesis (SHS) reaction. Merzhanov et al. put forward the following empirical criterion, that is, only when $T_{a d}>1800 \mathrm{~K}$, the SHS response can be self-sustained (25). Munir found that the ratio of the heat of formation of some compounds below their melting point to the heat capacity at $298 K$ has a linear relationship with $\Delta H_{298}^{\theta} / \Delta C p_{298}$ and $T_{a d}(29,30)$. It can be concluded that the reaction can maintain itself only when $\Delta H_{298}^{\theta} / \Delta C p_{298} \geq 2000 K$ (corresponding to $T_{a d} \geq 1800 \mathrm{~K}$ ). Otherwise, only the outside world can supplement energy into the system, such as by using a "preheating", "chemical furnace" or the use of "thermal explosion" methods to maintain self-reaction.

$$
A(s)+B(s) \rightarrow A B(s)+\Delta H
$$

Taking the enthalpy of the system as the state function, the heat released during the reaction is:

$$
\Delta H=\Delta H_{298}^{\theta}+\int_{298}^{T a d} \Delta C p d T
$$

in which $\Delta H_{298}^{\theta}$ is the standard enthalpy for formation of the product at a temperature of $298 \mathrm{~K}$, and $\triangle C p$ is the heat capacity of the product.

When adiabatic, the thermal effect of the system is $\Delta H=0$, and the adiabatic temperature $T_{a d}$ can be calculated in the following situations:

a. When $T_{a d}<T_{m p}$ :

$$
-\Delta H_{298}^{\theta}=\int_{298}^{T a d} \Delta C p d T
$$

b. When $T_{a d}=T_{m p}$ :

$$
-\Delta H_{298}^{\theta}=\int_{298}^{T a d} \Delta C p d T+\gamma \Delta H_{m}
$$

in which $\Delta H_{298}^{\theta}$ is the enthalpy of the product in the molten state, and $\Delta C p_{298}$ is the heat of fusion of the product.

c. When $T_{a d}>T_{m p}$ :

$$
-\Delta H_{298}^{\theta}=\int_{298}^{T a d} \Delta C p d T+\Delta H_{m}+\int_{T m p}^{T a d} \Delta C p d T
$$

It can be calculated approximately with the following equation:

$$
C p=a+b \times 10^{-3} \times T+c \times 10^{5} T^{-2}+d \times 10^{-6} T^{2}
$$

\section{Calculation of Gibbs free energy}

The Gibbs free energy change $\Delta G$ is a criterion for determining whether a chemical can proceed spontaneously under constant temperature and pressure conditions (31). The Gibbs free energy in the standard state can roughly reflect the possibility of a reaction or reaction trend. If $\Delta G^{\theta}<0$ in the system, the reaction process is irreversible and proceeds spontaneously. If it is $\Delta G^{\theta}=0$, the reaction process is reversible and spontaneous. And if it is $\Delta G^{\theta}>0$, the reaction cannot proceed spontaneously. 


$$
V_{1} B_{1}+V_{2} B_{2}+\ldots \rightarrow V_{j} B_{j}+\ldots
$$

In equation (7), $V_{i}$ is the measurement coefficient of the element or compound $B i$.

The calculation equation for the change of its standard free energy is:

$$
\Delta G^{\theta}=\sum v_{i} G_{i} T
$$

In the equation (8), $G_{i}, T$ is the free energy of the element or compound B at temperature $T$.

In the $\mathrm{Al}_{2} \mathrm{O}_{3}-\mathrm{B}_{2} \mathrm{O}_{3}-\mathrm{Mg}$ system, the following chemical reactions generally occur:

$$
\begin{gathered}
\mathrm{Al}_{2} \mathrm{O}_{3}+3 \mathrm{Mg} \rightarrow 2 \mathrm{Al}+3 \mathrm{MgO} \\
\mathrm{B}_{2} \mathrm{O}_{3}+3 \mathrm{Mg} \rightarrow 2 \mathrm{~B}+3 \mathrm{MgO} \\
\mathrm{Al}+12 \mathrm{~B} \rightarrow \mathrm{AlB}_{12} \\
\mathrm{Al}_{2} \mathrm{O}_{3}+12 \mathrm{~B}_{2} \mathrm{O}_{3}+39 \mathrm{Mg} \rightarrow 2 \mathrm{AlB}_{12}+39 \mathrm{MgO}
\end{gathered}
$$

Table 1 shows the free energy changes. A more systematic study of the thermodynamics of related reaction systems, prediction of the phases that may exist and appear in the reactants and products from the perspective of thermodynamics, provides a theoretical basis for the regulation of the self-propagating high-temperature synthesis process.

Table 1 The relation between free energy and temperature of different reactions

\begin{tabular}{lll}
\hline \multicolumn{1}{c}{ Equation } & \multicolumn{1}{c}{$\Delta \boldsymbol{G}^{\boldsymbol{\theta}}=\boldsymbol{A}+\boldsymbol{B} \boldsymbol{T}(\mathbf{k J} / \mathbf{m o l})$} & \multicolumn{1}{c}{ Temperature range/K } \\
\hline $\mathrm{Al}_{2} \mathrm{O}_{3}+3 \mathrm{Mg} \rightarrow 2 \mathrm{Al}+3 \mathrm{MgO}$ & $-128.01584+0.00792 \mathrm{~T}$ & $273-893$ \\
& $-139.08535+0.01888 \mathrm{~T}$ & $893-2303$ \\
$\mathrm{~B}_{2} \mathrm{O}_{3}+3 \mathrm{Mg} \rightarrow 2 \mathrm{~B}+3 \mathrm{MgO}$ & $-262.37839+0.07233 \mathrm{~T}$ & $2303-2573$ \\
& $-532.60705+0.05814 \mathrm{~T}$ & $273-723$ \\
& $-559.15828+0.0947 \mathrm{~T}$ & $723-853$ \\
$\mathrm{Al}+12 \mathrm{~B} \rightarrow \mathrm{AlB}_{12}$ & $-600.18482+0.13789 \mathrm{~T}$ & $853-2353$ \\
& $-505.72672+0.09833 \mathrm{~T}$ & $2353-2573$ \\
$\mathrm{Al}_{2} \mathrm{O}_{3}+12 \mathrm{~B}_{2} \mathrm{O}_{3}+39 \mathrm{Mg} \rightarrow 2 \mathrm{AlB}_{12}+39 \mathrm{MgO}$ & $-220+0.00745 \mathrm{~T}$ & $933-2473$ \\
& $-825.48067+0.23708 \mathrm{~T}$ & $2473-2789.5$ \\
\hline
\end{tabular}

\section{Result of calculation}

The adiabatic temperature was calculated using HSC6.0 software, and the adiabatic temperature of the reactions is $2789.5 \mathrm{~K}$. Previous studies have shown that the reaction temperature of self-propagating preparation of $\mathrm{AlB}_{12}$ exceeds $2300{ }^{\circ} \mathrm{C}(2573 \mathrm{~K})$. This tested result matches the calculation result. Since $=2789.5 \mathrm{~K}>1800 \mathrm{~K}$, self-propagation can proceed smoothly. Note that the reaction always has $\Delta G^{\theta}<0$ in table 1 , so the reaction can proceed spontaneously. 


\section{Summary}

The calculation results of preparing $\mathrm{AlB}_{12}$ using $\mathrm{Mg}, \mathrm{Al}_{2} \mathrm{O}_{3}$ and $\mathrm{B}_{2} \mathrm{O}_{3}$ as the raw materials shows that the adiabatic temperature of the system is $2789.5 \mathrm{~K}$, which meets the self-propagating reaction conditions. The calculated results are consistent with the actual test results. The Standard Gibbs free energy of the reaction formula is less than zero, which also proves the possibility of self-propagating reactions.

\section{Notes}

The authors declare no competing financial interest.

\section{Acknowledgements}

This work was supported by Fundamental scientific research business expenses of central universities (award \# N10060200).

\section{References}

1. V. I. Matkovich, Boron and refractory borides (Springer, 1977).

2. X. Luo et al., Influence of metallic additives on densification behaviour of hot-pressed $\mathrm{TiB}_{2}$. Light Metals, 1151-1155 (2009).

3. A. A. Shiriev, A. S. Mukasyan, "Thermodynamics of SHS Processes" in Concise Encyclopedia of Self-Propagating High-Temperature Synthesis. (Elsevier, 2017), pp. 385-387.

4. W. Tao et al. (2009) Finite element analysis of thermo-electric coupled field in 400kA large-scale aluminum reduction cell. in 2009 World Non-Grid-Connected Wind Power and Energy Conference (IEEE), pp 1-4.

5. X. Cao et al., Effect of $\mathrm{Ni}$ addition on pressureless sintering of tungsten diboride. International Journal of Refractory Metals and Hard Materials 41, 597-602 (2013).

6. X. Cao et al. (2011) High temperature electrochemical synthesis of tungsten boride from molten salt. in Advanced Materials Research (Trans Tech Publ), pp 463-466.

7. V. Yukhvid, Modifications of SHS processes. Pure and Applied Chemistry 64, 977-988 (1992).

8. C. Wang, X. Xue, X. Cao, H. Yang, Effect of BN Addition on Mechanical Properties and Microstructure of $\mathrm{TiB}_{2}-\mathrm{Al}$ Composites. Journal of Northeastern University (Natural Science), 19 (2012).

9. W. Chao et al., A New Method of Fabricating AlN-TiB2 Composite Ceramics. Materials and manufacturing processes 28, 953-956 (2013).

10. C. Wang, J. Zhang, X. X. Xue, X. Z. Cao (2013) Fabrication B-Ni-Al Shielding Materials by Vacuum Metal Infiltration. in Advanced Materials Research (Trans Tech Publ), pp 410-413.

11. P. Zhang, T. Xia, G. Zhang, L. Yan, W. Zhao, Thermodynamic analysis of Ti powder synthesized by SHS thermitreaction. Transactions of Nonferrous Metals Society of China 17, s27-s31 (2007).

12. X. Cao et al., Electrochemical Behavior and Electrodeposition of Sn Coating from Choline Chloride-Urea Deep Eutectic Solvents. Coatings 10, 1154 (2020).

13. H. C. Yi, J. Moore, Self-propagating high-temperature (combustion) synthesis (SHS) of powder-compacted materials. Journal of materials Science 25, 1159-1168 (1990).

14. W. Zhang et al., Effect of $\mathrm{Cr}$ content on the SHS reaction of $\mathrm{Cr}-\mathrm{Ti}-\mathrm{C}$ system. Journal of alloys and compounds 465, 127-131 (2008). 
15. X. Cao, C. Wang, X. Xue, H. Yang, Preparation of tungsten boride ceramic by pressureless sintering. Journal of Inorganic Materials 29, 498-502 (2014).

16. X. Cao, C. Wang, X. Xue, G. Cheng, Effect of ti addition on the residual aluminium content and mechanical properties of the $\mathrm{B}_{4} \mathrm{C}$-al composites produced by vacuum infiltration. Archives of Metallurgy and Materials 60, 2493-2398 (2015).

17. M. Dong et al., A novel comprehensive utilization of vanadium slag: as gamma ray shielding material. Journal of hazardous materials 318, $751-757$ (2016).

18. C. Wang et al., Research Progress on Aluminum-Boron Compounds (Al-B) and Its Composite Materials. Bulletin of the Chinese Ceramic Society, 26 (2013).

19. S. Mamyan (2002) Thermodynamic analysis of SHS processes. in Key Engineering Materials (Trans Tech Publ), pp 1-8.

20. W. Chao, X. Xiangxin, C. Xiaozhou, Y. He, C. Gongjin, The effect of Ti addition on the microstructure and fracture toughness of $\mathrm{BN}-\mathrm{Al}$ composite materials synthesized by vacuum infiltration. Archives of Metallurgy and Materials 58, 509--512 (2013).

21. A. Shiryaev, M. Nersesyan, Q. Ming, D. Luss, Thermodynamic feasibility of SHS of SOFC materials. Journal of Materials Synthesis and Processing 7, 83-90 (1999).

22. D. Qi et al., Preparation and Erosion Performance for Co-continuous Phase Composites of $\mathrm{Si}_{3} \mathrm{~N}_{4} / 1 \mathrm{Cr} 18 \mathrm{Ni}$ TTi. Chinese Journal of Materials Research 33, 34-42 (2019).

23. C. Wang, M. E. Hossain Bhuiyan, S. Moreno, M. Minary-Jolandan, Direct-Write Printing Copper-Nickel $(\mathrm{Cu} / \mathrm{Ni})$ Alloy with Controlled Composition from a Single Electrolyte Using Co-Electrodeposition. ACS Applied Materials \& Interfaces 12, 18683-18691 (2020).

24. M. Mahmoudi et al., Three-Dimensional Printing of Ceramics through "Carving" a Gel and "Filling in" the Precursor Polymer. ACS Applied Materials \& Interfaces 12, 31984-31991 (2020).

25. A. Merzhanov, History and recent developments in SHS. Ceramics international 21, 371-379 (1995).

26. D. Gosset, M. Guery, B. Kryger (1991) Thermal properties of some boron - rich compounds ("BnC" and $\mathrm{AlB}_{12}$ ). in AIP Conference Proceedings (American Institute of Physics), pp 380-383.

27. C. Wang et al. (2014) Elementary research on preparation of $\mathrm{AlB}_{12}$ powder by self-propagating high-temperature synthesis (SHS). in Materials Science Forum (Trans Tech Publ), pp 365-369.

28. A. Shiryaev, Distinctive features of thermodynamic analysis in SHS investigations. Journal of engineering physics and thermophysics 65, 957-962 (1993).

29. Z. Munir, Reaction synthesis processes: mechanisms and characteristics. Metallurgical Transactions A 23, 7-13 (1992).

30. S. Gennari, U. A. Tamburini, F. Maglia, G. Spinolo, Z. A. Munir, A new approach to the modeling of SHS reactions: Combustion synthesis of transition metal aluminides. Acta materialia 54, 2343-2351 (2006).

31. A. Masoudian, M. Karbasi, F. SharifianJazi, A. Saidi, Developing Al2O3-TiC in-situ nanocomposite by SHS and analyzingtheeffects of Al content and mechanical activation on microstructure. Journal of Ceramic Processing Research 14, 486-491 (2013). 